\title{
DO TRAUMÁTICO AO TRAUMA: A LÓGICA DO PRESENTE PERMANENTE
}

\author{
FROM TRAUMATIC TO TRAUMA: THE PERMANENT PRESENT LOGIC \\ DE LO TRAUMÁTICO AL TRAUMA: LA LÓGICA DEL PRESENTE PERMANENTE
}

\author{
Perla Klautau* \\ Monah Winograd" \\ Flávia Sollero-de-Campos ${ }^{* * *}$
}

\begin{abstract}
RESUMO
A partir do atendimento psicanalítico de pacientes portadores de lesões cerebrais, foi possível formular a hipótese de que, em muitos casos, o quadro psicopatológico que se instala após a percepção e a experiência das sequelas de adoecimentos neurológicos pode ser localizado em algum ponto entre a neurose traumática e as patologias narcísico-identitárias. Para fundamentar e ilustrar o desenvolvimento teórico dessa hipótese, apresentaremos um caso clínico no qual a compulsão à repetição é convocada como mecanismo de defesa: a experiência subjetiva de adoecimento neurológico é vivida como um golpe traumático que divide a vida entre um antes e um depois. A consequência disso é que os recursos para a elaboração psíquica são roubados, criando ou intensificando zonas psíquicas não integradas. Desse modo, é instalada uma temporalidade baseada em um presente permanente, isto é, num tempo que não fica para trás e tampouco fornece uma abertura para o que está por vir.
\end{abstract}

Palavras-chave: Trauma. Neurose traumática. Sofrimento narcísicoidentitário. Compulsão à repetição.

\begin{abstract}
Based on the psychoanalytic treatment of patients with brain injury, it was possible to formulate the hypothesis that, in many cases, the psychopathological condition that sets in after the perception and experience of Sequelae from neurological illnesses can be centralized in a place between
\end{abstract}

Texto recebido em 16 de agosto de 2013 e aprovado para publicação em 3 de agosto de 2015.

Apoios da FAPERJ (Processos n.os E.26/101.498/2010 e E.26/102.784/2011) e do CNPq (Processo n.o 305175/2012-2).

Professora dos Programas de Mestrado e Doutorado em Psicanálise, Saúde e Sociedade na Universidade Veiga de Almeida; psicanalista; membro efetivo do CPRJ. Endereço: Rua Ibituruna, 108, casa 3 - Maracanã, Rio de Janeiro-RJ, Brasil. CEP: 20171-901. E-mail: pklautau@icloud.com.

* Professora no Programa de Pós-Graduação em Psicologia Clínica da Pontifícia Universidade Católica do Rio de Janeiro (PUC Rio); psicanalista. Endereço: Rua Professor Luiz Castanhede, 130, ap. 302 - Laranjeiras, Rio de Janeiro-RJ, Brasil. CEP: 22245040. E-mail: monahwinograd@icloud.com.

${ }^{* * *}$ Professora no Programa de Pós-Graduação em Psicologia Clínica da PUC Rio. Endereço: Rua Gilberto Cardoso, 300, ap. 501 - Leblon, Rio de Janeiro-RJ, Brasil. CEP: 22430-070. E-mail: fsollero@uol.com.br. 
traumatic neurosis and the narcissistic-identity disorders. To support and illustrate the theoretical development of this hypothesis, we present a case in which the repetition compulsion is conveyed as a defense mechanism: the subjective experience of neurological illness is experienced as a traumatic blow that divides life between before and and after. The consequence of this is that resources for mental development are diverted, creating or intensifying non-integrated psychic areas. Therefore it is installed a temporality based on a permanent present, that is, in a time that does not fall behind nor provides a foot hold for what is to come.

Keywords: Trauma. Traumatic neurosis. Narcissistic-identity disorders. Repetition compulsion

\section{RESUMEN}

El tratamiento psicoanalítico de pacientes con lesiones cerebrales ha permitido formular la hipótesis de que, en muchos casos, la condición psicopatológica que se instala después de la percepción y la experiencia de las secuelas de daños neurológicos puede ser localizado en algún punto entre la neurosis traumática y las patologías de identidad narcisista. Para fundamentar e ilustrar el desarrollo teórico de esta hipótesis, se presenta un caso clínico en el cual la compulsión a la repetición fue convocada como un mecanismo de defensa: la experiencia subjetiva de la enfermedad neurológica se experimenta como un golpe traumático que divide la vida entre un antes y un después. La consecuencia de esto es que los recursos para la elaboración psíquica son robados, creando o intensificando zonas psíquicas no integradas. Por lo tanto, se instala una temporalidad en base a un presente permanente, es decir, un tiempo que no vuelve atrás ni ofrece una apertura para lo que está por venir.

Palabras clave: Trauma. Neurosis traumática. Sufrimiento de identidad narcisista. Compulsión por la repetición.

\section{INTRODUÇÃO}

m linhas gerais, é possível afirmar que o golpe traumático divide a vida
entre um antes e um depois e rouba os recursos para a elaboração psíquica.
A consequência disso é a criação ou intensificação de zonas psíquicas não
integradas, a inscrição de marcas e traços siderantes que atualizam angústias e
fantasias originárias, disparando ou amplificando o mecanismo de compulsão
à repetição, em uma tentativa ininterrupta de processamento e descarga. Sem
recursos simbólicos capazes de engendrar um trabalho elaborativo, a compulsão
à repetição, muitas vezes, é convocada como meio de atualizar o evento 
traumático. De acordo com essa lógica, é instaurada uma temporalidade baseada em uma noção de presente permanente, isto é, em um tempo que não passa e tampouco fica para trás. Em casos como esses, o grande desafio é construir uma narratividade com base na qual seja possível estabelecer uma via de elaboração para o golpe traumático, permitindo uma historicização capaz de inaugurar um outro passado e um futuro novo.

Com base nas pesquisas Do cérebro à palavra: a clínica com pacientes neurológicos e Aspectos subjetivos do adoecimento neurológico, ambas realizadas na Pontifícia Universidade Católica do Rio de Janeiro (PUC-Rio) e com o apoio do Conselho Nacional de Pesquisa (CNPq) e da Fundação Carlos Chagas Filho de Amparo à Pesquisa do Estado do Rio de Janeiro (FAPERJ), ${ }^{1}$ pretendemos formular a hipótese de que, em muitos casos, o quadro psicopatológico que se instala após a percepção e a experiência das sequelas de adoecimentos neurológicos pode ser localizado em algum ponto entre a neurose traumática e as patologias narcísicoidentitárias. Esta última terminologia vem sendo usada para designar o conjunto de características referentes a sofrimentos narcísicos nos quais o sujeito está ameaçado em seu sentimento identitário. $\mathrm{Na}$ maioria dos quadros, é possível observar falhas na constituição dos contornos do eu que produzem verdadeiros buracos no psiquismo e suscitam um tipo de angústia que difere da angústia neurótica de castração. Quando o eu não se encontra integrado como unidade separada do ambiente, a angústia suscitada diante da sensação de perda pode ser entendida como um temor de aniquilamento, de desmoronamento de um eu que, paradoxalmente, não se encontra constituído como tal. Já, quando é feita referência à expressão neurose traumática, supõe-se um eu integrado e entendese que a incidência do fator traumático revela uma estrutura preexistente. Em 1920, Freud define que esse tipo de neurose está ligado a uma situação em que o sujeito sente sua vida ameaçada em razão de um acontecimento impactante que o invade e captura toda e qualquer possibilidade de reação. Na maioria dos casos, é possível localizar a evidência de um golpe traumático na origem da neurose, o qual constitui o conteúdo da sintomatologia desencadeada. Nas neuroses traumáticas, os sintomas aparecem como uma tentativa repetida de ligar, de simbolizar o acontecimento traumático (Laplanche \& Pontalis, 1982).

Para fundamentar, apoiar e ilustrar o desenvolvimento teórico dessa hipótese, apresentaremos, a seguir, o caso de um homem de meia idade que, após ter sofrido dois acidentes vasculares encefálicos (AVE) isquêmicos, ${ }^{2}$ desenvolveu disfunções 1 Apoios da FAPERJ (Processos n.os E.26/101.498/2010 e E.26/102.784/2011) e do CNPq (Processo n.o 305175/2012-2).

2 De início súbito e usualmente conhecido como derrame cerebral, o AVE ou cerebral se caracteriza pela perda rápida da função neurológica em questão, seja de um entupimento (isquemia), seja de um rompimento (hemorragia) dos vasos sanguíneos cerebrais. No caso dos AVE isquêmicos, que são os tipos mais comuns, ocorre falta de fluxo sanguíneo cerebral, levando ao sofrimento e enfarte do parênquima do sistema nervoso. Embora, inicialmente, não haja morte de tecido cerebral, a falta de suprimento sanguíneo provoca a rápida degeneração do tecido, levando a área central do acidente vascular à morte em pouco tempo, podendo ocasionar disfunçôes cognitivas importantes e graves. 
cognitivas irremediáveis e graves, com reflexos importantes, por exemplo, na apreensão da identidade ao longo do tempo. Esse fato dificulta o reconhecimento de si no plano imaginário (especular) e simbólico. Entre um passado, no qual o corpo e as funções cognitivas estavam em perfeito funcionamento, e um futuro inaceitável, porque limitado e empobrecido relativamente à vida anterior, Pedro se paralisa diante do sentimento de perda de uma parte de si.

O início do atendimento psicanalítico a pacientes portadores de lesões cerebrais geralmente é marcado por pedidos de restauração e de reconstrução do que foi perdido. Por trás dessa demanda, há a crença de que é preciso recuperar as funções cognitivas para retomar os lugares ocupados nas relações sociais, familiares e de trabalho. Devido às limitações impostas pelas lesões cerebrais é evidente que o analista não pode se pautar pela recuperação de lembranças que a memória não pode mais acessar: como nas patologias narcísico-identitárias, o material disponível para o trabalho analítico pertence muito pouco ao registro da representação. Ao evocar o passado sem conseguir transformá-lo em lembranças dizíveis, estes pacientes experimentam sentimentos intensos e expressivos da memória afetiva.

Acreditando ser somente pelos afetos que uma via de (re)construção e de elaboração subjetiva podem ser instauradas, entendemos que a função do analista consistiria em estabelecer, com o paciente, um campo transferocontratransferencial que privilegie os afetos como ferramenta clínica. Quando possível, esse trabalho permitiria algum manejo psíquico das rupturas vividas e a atualização de questóes anteriores ao adoecimento, permitindo, assim, que sejam elaboradas e, consequentemente, tragam consigo outras novas a serem investigadas.

Embora em Freud sejam muito escassas as passagens nas quais a questão da contratransferência foi abordada diretamente, os pós-freudianos fizeram dela objeto de atenção crescente, sobretudo pelo tratamento ter sido paulatinamente entendido como uma relação e estendido ao acolhimento de crianças e de psicóticos. De modo bastante esquemático, Laplanche \& Pontalis (1982) lembram que a delimitação do conceito tem sido extremamente variada, pois se alguns o entenderam como tudo o que da personalidade do analista interviria no atendimento, outros restringiram a contratransferência aos processos psíquicos (conscientes ou inconscientes) que a transferência do paciente engendra no analista (por exemplo, Heimann, 1995). Neste último sentido, transferência e contratransferência não seriam processos distintos e separados, um do lado do paciente e outro do lado do analista, mas comporiam o campo analítico em conjunto. Já para Lacan (1953-1954/1986), a própria noção de contratransferência não teria objeto, pois se referiria aos efeitos da transferência 
sobre o desejo do analista que, ao ser posto no lugar do Outro pela palavra do analisando, ocuparia uma terceira posição que tornaria a relação analítica irredutível a uma relação dual. Apesar das críticas ferozes, o conceito prosperou ao longo da história, inspirando autores contemporâneos como Ogden (1994), para quem, entre analista e analisando, existe uma relação dialética intersubjetiva que engendra o que ele chamou de terceiro analítico, ou seja, uma criação comum do par analista-paciente, um campo transferencial-contratransferencial composto, entre outros, pela produção associativa de ambos. Ou seja, o terceiroanalítico é uma criação do analista e do analisando, ao mesmo tempo em que analista e analisando são criados pelo terceiro analítico.

\section{O GOLPE TRAUMÁTICO E A EXPERIÊNCIA SUBJETIVA DE ADOECIMENTO NEUROLÓGICO}

Pedro, homem de meia idade, sofreu dois AVE isquêmicos com um intervalo de aproximadamente 15 meses entre cada um. O primeiro ocorreu quando capinava o terreno de sua casa de veraneio. Após esse episódio, Pedro apresentou problemas na fala e paralisia em uma das pernas, tendo ficado licenciado por poucos meses. Depois de alguns meses de sua volta ao trabalho, durante uma discussão da qual relata ter sido ameaçado de morte e ficado muito nervoso, sofreu o segundo AVE. Pedro foi novamente licenciado e expressou, já nos primeiros atendimentos, a vontade de ser aposentado por invalidez devido ao fato de não ter condições de executar as tarefas exigidas pela posição de auxiliar escolar que ocupava.

Contudo a constatação desse limite era experimentada por ele como um sentimento de menos valia. Quando questionado se não poderia desempenhar outras tarefas, a resposta era sempre negativa e acompanhada da seguinte justificativa: "Se não dá para ser como antes, é melhor não fazer mais nada. Prefiro não trabalhar. Mas eu sou teimoso, vou voltar a fazer tudo que fazia. Sempre aguentei tudo, não é agora que vou desistir. Você vai ver"; fala repetida sempre que Pedro se deparava com situações que expunham as sequelas graves dos AVE sofridos, como ilustra sua reação diante de um sintoma que ele chamava de risada frouxa. Em verdade, essa risada é uma das manifestações clínicas da síndrome pseudobulbar (paralisia dos músculos de inervação bulbar causada por um comprometimento supranuclear), nas quais o quadro clínico é dominado por perturbações da fonação e da deglutição, relacionadas com um déficit do comando da língua, do véu palatino, da faringe e da laringe. Aos déficits, associam-se a espasticidade e os fenômenos de liberação da mímica automática: risos e choros espasmódicos; exatamente o que Pedro apresentava nas sessões 
quando entrava em contato com algo que mobilizava seus afetos, um misto de engasgo, choro engolido e risada. Durante o tratamento, a manifestação clínica da síndrome pseudobulbar ou, nos termos de Pedro, a risada frouxa passou a funcionar como uma bússola, fornecendo, para a analista, um indicativo da gradação das emoções e das angústias de Pedro e, para ele, possíveis sinais de melhora ou de piora. Sua lógica era a seguinte: quanto menor o número de risadas frouxas, maior a sua capacidade de aguentar, de se controlar; sinal de melhora. $\mathrm{O}$ inverso era sinal de que ele precisava aguentar mais, "estar pronto para o que desse e viesse".

Profundamente ligados ao sentimento de perda provocado pelas lesões cerebrais, os afetos despertados pela manifestação dessa espécie de ato expressivo e comunicativo deixavam-no mobilizado. Se as palavras lhe escapavam nos momentos em que tentava exprimir seus pensamentos, a função da analista era construir, junto com ele, um campo transfero-contratransferencial que privilegiasse a expressão e a comunicação afetiva como ferramenta clínica. Quando a risada frouxa foi articulada aos afetos que ela manifestava, o processo comunicativo e sobretudo expressivo ampliou-se, comportando e destacando a presença sensível da analista na sessão. Os processos perceptuais e cognitivos da analista foram usados como suporte para facilitar a compreensão dos afetos expressos de forma não verbal pelo paciente: diante do engasgo provocado pela risada, o trabalho era nomear e criar legendas para os sentimentos que brotavam: "Pedro, sinto que, quando sua risada afrouxa e você se engasga, tem alguma coisa que está difícil de sair, de dizer, de colocar em palavras". Ao que Pedro respondia com muita dificuldade: "É vergonha do fracasso". Se as primeiras sessões duravam não mais que 30 minutos, sendo metade ocupada pela risada, aos poucos ela foi se retirando, e Pedro conseguia permanecer mais tempo no atendimento: sua risada frouxa tinha aberto a possibilidade de um canal narrativo.

Após alguns meses, relatou ter sentido uma melhora considerável: "Estou vindo para cá sozinho, e olha que é longe!". As perdas e os limites decorrentes do AVE eram encarados como sinal de incapacidade e suas conquistas como sinais de que voltava a ser como era antes. Demonstrava satisfação enorme quando vinha ao atendimento desacompanhado, exibindo esse seu feito como uma medalha de bom desempenho. $\mathrm{O}$ mesmo acontecia quando passava uma sessão sem apresentar sua risada frouxa, por ele considerada sinal de descontrole, levando a analista a perguntar: "Mas, por que você não pode se descontrolar? Por que não pode se emocionar?”. Pedro contou ter passado por dificuldades durante a infância e que, talvez por isso, tenha sido criado escutando que tinha de ser forte: "Comida na mesa nunca faltou, mas, com onze irmãos, era difícil ter o carinho de mãe. Ela nunca deixou faltar nada, sempre cuidou de tudo. Fez questão que 
os filhos homens tivessem estudo. Nossa roupa era passada e engomada, quem voltava com uniforme sujo sabia que ia apanhar". Pedro, então, descreveu seu pai como um homem muito inteligente, mas que sempre lamentou o fato de nunca ter tido a oportunidade de estudar: "Eu sempre tive vontade de estudar, queria dar esse orgulho para meu pai. Eu fui o único dos filhos que se formou. Eu sou o único que tem um diploma".

Depois de alguns meses de tratamento, Pedro e sua família mudaram de casa e iniciaram uma reforma. Esses dois acontecimentos se tornaram assuntos constantes das sessões, pois a reforma e a dificuldade de realizar algumas tarefas ao lado dos pedreiros fizeram com que Pedro experimentasse profundamente os limites impostos pelo adoecimento neurológico; experiência que conduziu sua análise aos vestígios de traumas precoces. A partir daí, Pedro voltou a ficar inquieto e a se agitar durante as sessões, não suportando o atendimento por mais de 30 minutos, e metade da sessão voltou a ser ocupada por sua risada frouxa.

Quando criança, Pedro não podia falhar. Além de si, precisava cuidar dos irmãos mais novos e ajudar o pai a garantir o sustento da casa:

Morei na roça até uns 10 anos. Antes disso, não estudei. Ia cedo com meu pai para a lavoura e, quando chegava, tinha que ajudar a minha mãe. Eu ficava com meus irmãos, ajudava no banho e limpava a sujeira. Só soube o que era brincar quando mudamos para o Rio e fui para a escola.

Durante seus relatos, demonstra tristeza ao acessar lembranças que o fazem acreditar ter cometido um grande erro:

Nós éramos muito simples, tudo que a gente tinha para comer era o que a gente plantava, as galinhas e o leite que as duas vacas davam. Meu pai comprou um cavalo que servia para ele ir mais longe, vender o que sobrava. Lembro que ele me deixou tomando conta do cavalo, e eu me distraí vendo uns meninos jogarem bolar de gude e perdi o cavalo. Corri, mas não consegui alcançar. Nunca vou me esquecer disso. Por minha causa, o cavalo fugiu. Nunca mais meu pai conseguiu comprar outro.

Neste momento, a analista interveio: "Trabalhar, cuidar dos seus irmãos e se responsabilizar pelo bem mais valioso da família eram tarefas muito grandes para um menino tão pequeno, assim como é, hoje em dia, ajudar os pedreiros na reforma de sua casa”. Parecia que o desamparo experimentado na infância se atualizava como traumático a partir das perdas derivadas dos AVE sofridos: em ambos, apresentava-se a ideia defensiva de ser preciso aguentar, de não poder falhar, ser forte e não desistir nunca. Essa ideia, atualizada, instaurava um estado permanente de traumatismo. 
Quando criança, Pedro foi impingido a se responsabilizar por algo além de sua capacidade: o bem mais valioso da família. Em 1923, com base nos sonhos relatados por seus pacientes, Ferenczi (2011d) cunhou o termo "bebê sábio" para denominar a criança que assume a posição de cuidador, invertendo o papel do ambiente no desenvolvimento infantil:

Não é raro ouvir pacientes contarem sonhos em que recém-nascidos, bebês de cueiros ou crianças muito pequenas, são capazes de falar ou escrever com perfeita desenvoltura, brindar seu meio com falas profundas ou sustentar conversas de erudito, proferir discursos, dar explicações científicas e assim por diante (p. 223).

Dez anos depois, Ferenczi (2011d) propôs que se pensasse o trauma como uma falha ambiental que resultaria no abandono da criança durante o processo de elaboração e produção de sentido (processo que não pode ser realizado sem a sustentação de um adulto). Na esteira de Ferenczi (e de7 Winnicott), Khan (1984) desenhou o conceito de trauma cumulativo para designar os efeitos de falhas repetidas da mãe em sua função de atender às necessidades egoicas do bebê. Para sustentar sua argumentação, Khan (1984) propôs uma aproximação com a famosa metáfora freudiana do escudo protetor:

Proponho-me aqui a examinar a função da mãe no seu papel de escudo protetor. Esse papel de escudo protetor constitui "o ambiente normal que se pode esperar" (Hartmann, 1939) para as necessidades anaclíticas do bebê. Meu argumento é que o trauma cumulativo resulta das fendas observadas no papel da mãe como escudo protetor durante todo o curso do desenvolvimento da criança, desde a infância até a adolescência - isto é, em todas as áreas de experiência onde a criança precisa da mãe como Eu auxiliar para sustentar suas funçóes de Eu, ainda imaturas e instáveis (p. 62).

Essas fendas não seriam traumáticas no momento em que se instalam, só adquirindo valor de trauma cumulativa e retrospectivamente, ou seja, o caráter traumático não derivaria dos acontecimentos no momento de sua ocorrência, no instante de abertura das fissuras, mas se instalaria pela repetição e pelo acúmulo de pequenos sulcos, silenciosa e invisivelmente. Noutras palavras, constituído pelo somatório das fendas acumuladas no eu ao longo do tempo, o fator traumático só seria percebido como tal após a instalação dos efeitos patogênicos das rachaduras acumuladas. Nesse ponto, vale a pena resgatar as ideias sobre a atemporalidade do inconsciente que giram em torno do termo alemão nachträglich (utilizado por Freud no que diz respeito à temporalidade da instauração do traumatismo), também denominado après-coup, em francês; a posteriori, em latim; e só depois, 
em português. Essas expressões devem ser entendidas como uma ressignificação retroativa de um dos componentes fundamentais da constituição do trauma psíquico: a ressignificação do que foi vivido em um tempo anterior. Não é difícil perceber a articulação dessa ideia com a falta de sustentação que Pedro obteve do ambiente durante os primeiros anos de sua vida. Até os 10 anos de idade, Pedro se adaptou ao ambiente da mesma forma que os bebês sábios de Ferenczi (2011d): provendo quando deveria estar sendo provido. Mas foi somente a partir da experiência de adoecimento neurológico que o desamparo do ambiente se atualizou como traumático. De acordo com essa lógica, é possível entender o sentido do termo alemão nachträglich: só depois, quando o atual aciona o infantil.

A atualização do caráter traumático da experiência de desamparo infantil exposta no caso em questão ficou ainda mais evidente quando as sequelas deixadas pelos AVE colocaram Pedro diante da impossibilidade de, durante a reforma de sua casa, trabalhar junto com os pedreiros e realizar tarefas antes consideradas simples e rotineiras. Assim, no início da reforma, sua esposa notou mudanças em seu comportamento: ele ficou muito nervoso, agitado e brigava constantemente com o filho. "Chegou a pegar uma faca", disse a esposa, mas, enquanto a mulher falava, Pedro apresentava sua risada e somente conseguia dizer duas coisas: "Quero acabar logo com esse sofrimento. Eu ia enfiar o facão na minha barriga". Durante algumas sessōes subsequentes, Pedro se deteve na constatação dolorosa de "não ser mais como era antes":

Eu sei que não posso fazer mais o que eu fazia antes, não sai, não me lembro das coisas, mas quero fazer, não consigo esperar. Quero que essa obra acabe logo, quero dar para a minha mulher o conforto que ela merece, tenho medo que ela morra e essa obra não acabe.

A analista interveio: "Isso você me contou quando falou da morte da sua mãe. Disse que seu pai não aguentou, chorou muito e repetia que tinha falhado, que não conseguiu dar para a sua mãe tudo que ela merecia”. Ao que Pedro respondeu: "Cresci sabendo que tinha que aguentar, que não podia falhar. E olha o que está acontecendo comigo". Pedro interpretava as limitaçôes impostas pelo adoecimento neurológico como o fracasso de seu projeto de ter êxito onde ele, na função de "bebê sábio", e seu pai, no desempenho de papel de provedor, não tiveram. Em transe, ao mesmo tempo paralisado e em busca de situações que impunham a constatação da impossibilidade de se responsabilizar por algo além de sua capacidade, Pedro ainda obedecia a seus pais: o presente permanente era o de sua infância, mais do que o dos AVE. Suas perdas cognitivas, aliadas ao mecanismo da compulsão à repetição, punham-no diante da exigência 
superegoica de aguentar tudo, atualizando seu sentimento de menos valia diante do insucesso no desempenho de tarefas, imposto por suas limitações.

Vê-se como, no caso de Pedro, o mecanismo de compulsão à repetição aparecia expresso em atos que giravam em torno da ideia de voltar a ser como antes e, por conta disso, ultrapassar sempre seus limites. No início do tratamento, enquanto tentava se adaptar à aposentadoria, insistia em desempenhar tarefas domésticas impossíveis de serem realizadas devido à sua condição, tais como subir em escadas para trocar lâmpadas, pendurar balóes em festas, subir na laje para consertar o telhado, etc. Preso no passado, não entendia o que lhe era possível agora, dizendo que estava treinando e que, um dia, conseguiria fazer e ser como antes de adoecer. Quando confrontado com os limites impostos por sua nova condição, respondia sem refletir: "Você vai ver, eu sou teimoso, não desisto, vou conseguir". Mas o período da reforma foi decisivo e permitiu à analista observar um deslocamento no conteúdo da repetição, pois, diante dos obstáculos encontrados durante o trabalho dos pedreiros, Pedro constatou que não tinha condições de emboçar paredes e nem de participar da instalação da parte elétrica, colocando a fiação da casa, etc. Foi quando passou a se interessar por caminhadas feitas com um grupo do antigo trabalho. Mas, muito engajado nessa nova atividade, somente participava de caminhadas que exigiam grande esforço físico:

Para ir com o grupo caminhar na praia, prefiro ficar em casa. Vou quando tem que subir, gosto de ir atrás do professor, vou guiando o grupo com ele. Mas não sei o que está acontecendo, não consigo mais ir na frente do grupo, tenho ficado para trás. Acho que não vou mais, se for para ficar para trás, junto com a terceira idade, prefiro ficar em casa.

Em última instância e no limite, Pedro fracassava e, diante desse fracasso, encontrava-se preso à ideia de que "se não dá para ser como antes, melhor ficar quieto, não fazer mais nada”.

Ao longo dos atendimentos, a hipótese de um início de demência vascular foi confirmada pelo neurologista e pela avaliação neuropsicológica realizada um ano após o início do tratamento. Durante as sessões de fonoaudiologia e na avaliação neuropsicológica, foi detectado um desempenho cognitivo globalmente prejudicado, com destaque para um comprometimento significativo da flexibilidade cognitiva. Ou seja, sua maior dificuldade era flexibilizar o pensamento, a fim de gerar estratégias para a solução de problemas, o que participava tragicamente de seu funcionamento psíquico já profundamente afetado e imobilizado pelo trauma. 


\section{TRAUMATISMO, TRAUMÁTICO E TRAUMA: TRÊS VARIAÇÕES NA OBRA DE FREUD}

No Vocabulário de psicanálise (Laplanche \& Pontalis, 1982), os termos "trauma" e "traumatismo" compõem um único verbete, tendo sido ambos importados da Medicina, mais especificamente, da prática cirúrgica. A etimologia da palavra "trauma" remete ao termo grego indicativo de "ferida", por sua vez, derivado do grego traumatós (furar), e seu significado pode ser descrito como uma ferida com efração. Já a palavra "traumatismo" estaria mais ligada às consequências do trauma no conjunto do organismo, resultantes da violência externa. Além dos dois termos tratados com sinônimos no verbete, existe um terceiro, comumente associado a eles: "traumático". Este deve ser compreendido como um acontecimento impactante em função da incapacidade do sujeito de reagir a ele. Durante sua montagem ao longo da obra freudiana e devido aos remanejamentos efetuados, o conceito psicanalítico de trauma englobou o campo semântico brevemente descrito acima. Bokanowisky (2002, 2005) propõe uma sistematização do conceito freudiano em três momentos, cada um deles articulado com um dos sentidos descritos. Sem entrar na discussão sobre a precisão dos períodos identificados pelo referido autor, é certo que, devido aos remanejamentos efetuados por Freud, o conceito de trauma assumiu, pelo menos, as três acepções mencionadas que podem ser aproximadas do funcionamento dos seguintes quadros clínicos: histeria, neuroses traumáticas e sofrimentos narcísicos-identitários.

De acordo com Bokanowisky (2002; 2005), a primeira acepção assumida pela palavra trauma é a de "traumatismo", cujo significado corresponde às consequências do trauma no conjunto do organismo. Seguindo o raciocínio do autor, traumatismo nomeia o primeiro momento da elaboração freudiana: de 1895 a 1920. Esse período encontra-se intimamente relacionado à teoria da sedução e à lógica do trauma em dois tempos. O caso Emma (Freud, 1895/1950/1990, p. 474-78) ${ }^{3}$ serve como exemplo paradigmático para o entendimento da instalação do traumatismo. Com o intuito de explicar a compulsão fóbica de sua paciente, Freud remonta a temporalidade do traumatismo. Para tal, recorre a duas cenas: a primeira (cena I) ocorre na puberdade, e a segunda (cena II), por volta dos 8 anos de idade. Na primeira cena, Emma entrou em uma loja e viu dois vendedores rindo juntos. Tomada por uma espécie de afeto de susto, saiu correndo da loja. Emma julgou que os dois estavam rindo de suas roupas e confessa que um deles a havia agradado sexualmente. A segunda cena recordada remonta à ocasião em que esteve desacompanhada em uma confeitaria e o proprietário agarrou-lhe as partes genitais por cima da roupa. Apesar disso, ela relata que voltou à confeitaria

3 A primeira data indica o ano de publicação original da obra e a segunda data indica a edição consultada pelo autor; que só será pontuada na primeira citação da obra no texto. Nas seguintes será registrada apenas a data de publicação original. 
mais uma vez e depois parou de ir. Emma estabelece um vínculo associativo entre as duas cenas: o riso.

$\mathrm{O}$ riso dos vendedores a fez lembrar-se do sorriso com que o proprietário da confeitaria acompanhou sua investida. A marcha dos acontecimentos agora pode ser reconstituída. $\mathrm{Na}$ loja, os dois vendedores estavam rindo; esse riso evocou (inconscientemente) a lembrança do proprietário. De fato, a segunda situação tinha ainda outra semelhança [com a primeira]: ela mais uma vez estava sozinha em uma loja. Juntamente com o dono da confeitaria, lembrou-se de que ele a agarrara por cima da roupa; de que desde então ela alcançara a puberdade. A lembrança despertou o que ela certamente não era capaz na ocasião, uma liberação sexual, que se transformou em angústia. Devido a essa angústia, ela temeu que os vendedores da loja pudessem repetir o atentado e saiu correndo (Freud,1895, p. 476).

Essa passagem ilustra a lógica da expressão que remonta à etiologia da histeria, cunhada "trauma em dois tempos": as consequências do acontecimento traumático só se estabelecem a posteriori. Ou seja, o traumatismo não se instala logo após o acontecimento traumático primevo, mas sim num segundo tempo. "Só depois", quando a lembrança da cena, despertada geralmente por um traço, aciona o que não pode ser vivido na época infantil. Sob essa ótica, traumatismo deve ser entendido como os danos psíquicos causados pelo acontecimento traumático resultante de uma violência externa.

O período em questão inclui também o remanejamento teórico efetuado por Freud (1897/1990) que concede o mesmo peso à realidade e à fantasia referente ao acontecimento traumático. Isso significa que a fantasia de sedução substitui o ato em si como fator traumático prínceps que presidiria a organização da neurose. Dessa forma, as situações traumáticas paradigmáticas estão ligadas às fantasias originárias e às angústias aferentes de sedução, de castração, cena primitiva, complexo de Édipo, etc. Desse modo, o traumatismo tem relação com a força das pulsões sexuais e com a luta do Eu. Diante disso, é possível dizer que, nesse primeiro tempo, a linguagem do trauma é a da histeria.

“Traumático" é o sentido empregado para definir o segundo momento demarcado por Bokanowisky (2002, 2005), que vai de 1920 a 1939. Nessa acepção, o trauma deve ser compreendido como um acontecimento impactante em razão da incapacidade do sujeito de reagir a ele. Os modelos teóricos desse período são as noções de falha na função de paraexcitação e desamparo, encontrados, respectivamente, nos artigos: Além do princípio do prazer (1920a/1990) e Inibiçôes, sintomas e ansiedade (1920b/1990). Em ambos, o destaque é dado ao fator econômico: há uma falha na função de paraexcitação do aparelho psíquico que resulta em uma efração quantitativa, isto é, em um afluxo de excitações que é excessivo em relação à tolerância do sujeito e à capacidade de denominar e elaborar psiquicamente essas excitações. Nas palavras de Freud: 
Descrevemos como "traumáticas" quaisquer excitações provindas de fora que sejam suficientemente poderosas para atravessar o escudo protetor. Parece-me que o conceito de trauma implica necessariamente numa conexão desse tipo com uma ruptura numa barreira sob outros aspectos eficaz contra os estímulos. Um acontecimento como um trauma externo está destinado a provocar um distúrbio em grande escala no funcionamento da energia do organismo e a colocar em movimento todas as medidas defensivas possíveis. Ao mesmo tempo o princípio do prazer é posto momentaneamente fora de ação. Não há mais possibilidade de impedir que o aparelho mental seja inundado com grandes quantidades de estímulos; em vez disso, outro problema surge, o problema de dominar as quantidades de estímulos que irromperam, e de vinculá-las, no sentido psíquico, a fim de que delas se possa então desvencilhar (Freud, 1920a, p. 45).

A neurose traumática pode ser a tradução clínica do que foi descrito acima. Esse quadro é definido pelos efeitos psíquicos decorrentes do atravessamento de situações nas quais existe um real perigo de morte. Isso proporciona ao eu um temor diante da possibilidade de experimentar um dano. Quando o aumento de excitação não pode ser contido, o princípio de prazer fracassa e produzem-se experiências traumáticas, promovendo um acúmulo de energias. Sem a lógica do princípio de prazer operante, a compulsão à repetição entra em cena com sua marca patente: a repetição do trauma. A função desse tipo de defesa é a de dominar o excesso de excitação provocado pelo acontecimento traumático. Os sonhos característicos das neuroses traumáticas ilustram esse mecanismo: diferentemente dos sonhos movidos pela busca de prazer e pela realização alucinatória de desejos, os sonhos traumáticos conduzem os pacientes, com regularidade, à situação em que o trauma ocorreu. Ao guiar o sujeito de volta ao acontecimento traumático, os sonhos repetitivos buscam dominar o excesso de estímulo e processar a ligação da energia livre. Porque a excitação não pode ser tramitada psiquicamente, dissolvendo a lógica de funcionamento segundo o princípio do prazer, o dispositivo de compulsão à repetição tornou-se ativo em um esforço simultâneo de descarga e de domínio da excitação não metabolizada. Nesse caso, as marcas do trauma congelam-se, impedindo suas retranscrições e sua articulação em uma rede representacional. Mas essa fixação no acontecimento traumático difere em essência da fixação libidinal, pois, se a última expressa classicamente uma ligação forte da libido a determinados modos de obtenção de satisfação e sua permanência em organizações características de suas fases de desenvolvimento, a primeira revela um movimento regressivo desorganizador como consequência da operação intensificada da pulsão de morte, mais além do princípio do prazer. Daí o entendimento de que os sonhos traumáticos repetitivos não se encontram orientados pela satisfação alucinatória dos desejos. 
No texto de 1926/1990, Freud continua associando o traumático à ideia de efração quantitativa, entretanto acrescenta um complemento fundamental: os perigos podem ser tanto de origem externa ao aparato psíquico quanto de origem interna. E mais: estabelece uma analogia entre o medo da morte característico dos quadros de neurose traumática e o medo da castração.

Estou inclinado, portanto, a aderir ao ponto de vista de que o medo da morte deve ser considerado como análogo ao medo de castração, e que a situação à qual o ego está reagindo é de ser abandonado pelo superego protetor - os poderes do destino -, de modo que ele não dispóe mais de qualquer salvaguarda contra todos os perigos que o cercam (Freud, 1926, p. 153).

A novidade contida neste trecho é que o eu reage da mesma maneira tanto diante de um real perigo de morte quanto da ameaça de perda do objeto. Freud aborda a castração de forma distinta do sentido habitual de mutilação do órgão sexual masculino. Em psicanálise, a castração designa a experiência inconsciente de ameaça experimentada perante a possibilidade de perda daquilo que é considerado como uma parte importante do próprio corpo. Nesse contexto, o desamparo diante da perda do objeto funciona como o paradigma da angústia por transbordamento. Tal ideia estabelece um recuo da teorização freudiana em direção às experiências traumáticas relacionadas à estruturação do psiquismo.

Os remanejamentos efetuados no segundo modelo do trauma revelam uma ligação entre trauma e os primórdios da vida psíquica que determina, de acordo com Bokanowisky $(2002,2005)$, o terceiro momento, cuja coroação acontece em 1939, mais precisamente em Moisés e o monoteísmo (Freud, 1939/1990). Finalmente a palavra trauma define este último momento. No referido artigo, Freud enfatiza a influência dos traumas precoces, ocorridos na primeira infância (até aproximadamente o quinto ano de idade), sobre o desenvolvimento das neuroses. "Denominamos traumas aquelas impressóes, cedo experimentadas e mais tarde esquecidas, a que concedemos tão grande importância na etiologia das neuroses" (Freud, 1939, p. 91). Mais adiante, complementa: "Os traumas são ou experiências sobre o próprio corpo do indivíduo ou percepções sensórias, principalmente algo visto ou ouvido, isto é, experiências ou impressões" (p. 93). Se reunirmos os elementos das duas passagens transcritas, é possível perceber que o trauma está relacionado à descrição de algo vivido que não pode ser definido de forma precisa, isto é, algo experimentado por meio de um conhecimento obtido através dos sentidos que, ao longo do tempo, deixa uma marca: vestígios e impressóes de um tempo anterior ao estabelecimento da linguagem. Nesse momento da constituição psíquica, a comunicação se realiza de forma não verbal. Aqui reside a novidade de circunscrever o trauma em um período tão 
inicial da vida psíquica. A consequência disso é a entrada em cena de operações defensivas precoces.

Nos primeiros anos do desenvolvimento, o eu infantil, a serviço do princípio de prazer, tem a tarefa de exercer uma mediação entre as exigências do isso e do mundo externo. Além de mediar as relações entre estas duas instâncias, cabe ao eu proteger o isso dos perigos oferecidos pelo mundo externo: durante esse processo, o eu passa a adotar uma posição defensiva não somente com relação aos perigos externos, mas também aos perigos internos (exigências do isso). Dessa forma, o eu lança mão dos mesmos repertórios de defesas quando se encontra tanto diante de um perigo de ordem interna quanto de um perigo de ordem externa. Um dos procedimentos utilizados é o de alterar a si próprio, adaptando-se à situação de perigo. De acordo com Freud (1933/1990, p. 152): "Determinadas modificações parecem ser definitivas e correspondem a cicatrizes que se formaram quando um processo completou o seu curso". O corolário dessa modalidade de defesa é que o eu sobrevive carregando cicatrizes adquiridas nos primeiros anos do desenvolvimento infantil.

As alteraçóes erigidas no eu, comparáveis a cicatrizes, aproximam a linguagem do trauma do funcionamento de quadros que a literatura pós-freudiana denomina, em sentido amplo, patologias narcísico-identitárias (Balint, 1994; Bion, 1994; Green, 1990; Roussillon, 2006; Winnicott, 2000a, 2000b). Esse tipo de sofrimento traz como marca patente a asfixia da vida psíquica: a área ferida, danificada por conta do acontecimento traumático é deixada fora do processo de ligação. "São, poder-se ia dizer, um Estado dentro de um Estado, um partido inacessível, com o qual a cooperação é impossível, mas que pode alcançar êxito em dominar o que é conhecido como partido normal e forçá-lo a seu serviço" (Freud, 1939, p. 95).

Assim como na neurose traumática, nas patologias narcísico-identitárias, vêse a compulsão à repetição dominar a cena psíquica na tentativa de elaborar o que permaneceu somente como marca ou traço e de descarregar a intensidade que não pode ser tramitada psiquicamente. Ao longo da vida, como fundo, o estado de desamparo somente se torna figura quando outras situações traumáticas atualizam as precocemente experimentadas. Se isso acontece, uma temporalidade baseada em uma noção de "presente permanente" é instaurada.

\section{ENTRE O TRAUMÁTICO E O TRAUMA: UM TEMPO QUE NÃO PASSA}

Se retomarmos as considerações efetuadas por Freud (1920a), em Além do princípio do prazer, uma experiência deve ser definida como traumática quando rompe o escudo protetor, inunda o aparelho psíquico com uma grande quantidade 
de estímulos e coloca em movimento todas as medidas defensivas possíveis. Para exemplificar essa ideia, Freud parte da seguinte hipótese: o aparelho psíquico originário comporta-se como uma vesícula viva que desenvolve um escudo protetor capaz de filtrar e atenuar os estímulos provenientes do exterior. Ao funcionar como um anteparo, o escudo protetor só transmite uma parte da intensidade das excitações ao sistema percepção-consciência. Se a barreira erigida pelo escudo protetor é rompida, a experiência torna-se traumática. Quando isso acontece, o princípio de prazer sai de cena e mecanismos de defesa anteriores à instauração do recalque são acionados.

Nove anos após a publicação do texto acima mencionado, Ferenczi (2011a) desloca a ênfase dada por Freud à função de escudo protetor do aparelho psíquico para o ambiente. Com isso, a relação estabelecida entre a criança e seu entorno passa a ser concebida como constitutiva da subjetividade. Em $A$ criança mal acolhida e sua pulsão de morte, Ferenczi (2011a) atribui à família e aos pais a função de amparar as crianças recém-chegadas ao mundo e postula que, desde muito cedo, estas registram os sinais conscientes e inconscientes de desamparo. Se recorrermos ao trabalho publicado quatro anos mais tarde, Confusão de língua entre os adultos e a criança (Ferenczi, 2011b), é possível entender que os sinais registrados da ausência de resposta do ambiente diante de uma situação de desamparo vão continuar presentes no psiquismo da criança, mesmo ainda não sendo nomeados como tais. A permanência desses sinais não representados no psiquismo e a falta de resposta do objeto serão conceituados como traumáticos por Ferenczi. Para fundamentar essa ideia, o mecanismo de sedução da criança pelo adulto é descrito como o paradigma da situação de desamparo pelo ambiente. Nesse sentido, a sedução deve ser entendida como uma violação psíquica.

As crianças sentem-se física e moralmente sem defesa, sua personalidade é ainda frágil demais para poder protestar, mesmo que em pensamento, contra a força e a autoridade esmagadora dos adultos que as emudecem, podendo até fazê-las perder a consciência. Mas esse medo, quando atinge seu ponto culminante, obriga-as a submeter-se automaticamente à vontade do agressor, a adivinhar o menor de seus desejos, a obedecer esquecendo-se de si mesmas, e a identificar-se totalmente com o agressor (Ferenczi, 2011b, p. 117, grifo do autor).

No modelo proposto por Ferenczi, o medo da criança transforma a identificação em incorporação, fazendo com que o agressor desapareça da realidade externa e passe a existir no registro intrapsíquico. Dessa forma, instala-se no interior da criança o sentimento de culpa do agressor: "O jogo até então anódino apresentase agora como um ato merecedor de punição” (Ferenczi, 2011b, p. 117). É justamente neste momento que se estabelece a confusão de línguas: a criança 
se sente, ao mesmo tempo, inocente e culpada. Diante de tal confusão, perde a confiança no testemunho de seus sentidos. É possível adicionar a isso a falta de sustentação do ambiente refletida pela desqualificação do afeto experimentado pela criança. Vejamos as palavras de Ferenczi:

De um modo geral, as relações com uma segunda pessoa de confiança - no exemplo escolhido, a mãe - não são suficientes íntimas para que a criança possa encontrar uma ajuda junto dela; algumas tênues tentativas nesse sentido são repelidas pela mãe como tolices. A criança de quem se abusou converte-se num ser que obedece mecanicamente, ou que se fixa em uma atitude obstinada; mas não pode mais explicar as razōes desta atitude (Ferenczi, 2011b, p. 117-118).

O desmentido é experimentado como violação, disparando o dispositivo da clivagem a partir da qual se observaria, simultaneamente, duas partes da personalidade em ação: uma estaria preservada, pois tudo sabe, mas nada sente; ao passo que a outra parte encontrar-se-ia destruída, destituída de valor por falta de confiança nos próprios afetos. O corolário disso é a obediência mecânica ao sentimento de culpa introjetada a partir da identificação com o agressor. Esse tipo de identificação origina, posteriormente, uma espécie de superego sádico, cujas exigências podem ser equiparadas às de um agressor implacável que ordena obediência a seus ditames. Tal obediência é descrita por Ferenczi (2011b) como uma espécie de transe traumático expressa pela compulsão à repetição.

Como já foi visto, a principal novidade do texto freudiano de 1920 está relacionada à natureza e à finalidade da recorrência da mesma coisa. Nesse mesmo ano, no Congresso de Haia, realizado meses antes da publicação de Além do principio de prazer (Freud, 1920a), Freud fez uma comunicação com o título Suplemento à teoria dos sonhos, na qual anuncia uma classe de sonhos que se apresenta como uma exceção à regra de que os sonhos são realizaçôes de desejo regidos pelo princípio do prazer: "Trata-se dos chamados sonhos 'traumáticos', que ocorrem em pacientes que sofreram acidentes, mas que aparecem também durante a psicanálise de neuróticos, trazendo-lhes de volta traumas esquecidos da infância" (Freud, 1920b, p. 15). A ideia contida em Além do princípio do prazer, publicado alguns meses depois, é que a nova classe de sonhos, ao direcionar o sujeito de volta ao evento traumático, busca dominar (por meio da repetição) o excesso de estímulo e processar a ligação da energia livre. Nesse contexto, agir repetidamente continua tendo o caráter de uma rememoração que ocupa o lugar de uma lembrança não integrada à cadeia representativa. Portanto o material que não é integrado nos sistemas psíquicos retorna e se repete, constituindo essa nova classe de sonhos que não visa à realização alucinatória dos desejos recalcados. A 
finalidade desse tipo de sonho é engendrar um trabalho de ligação para que o excesso possa ser elaborado e, finalmente, representado.

É, porém, impossível classificar como realização de desejo os sonhos que estivemos debatendo e que ocorrem nas neuroses traumáticas, ou sonhos tidos durante as psicanálises, os quais trazem à lembrança os traumas psíquicos da infância. Eles surgem antes em obediência à compulsão à repetição, embora seja verdade que, na análise, essa compulsão é apoiada pelo desejo (incentivado pela sugestão) de conjurar o que foi esquecido e reprimido. Dessa maneira, pareceria que a função dos sonhos, que consiste em afastar quaisquer motivos que possam interromper o sono, através da realização dos desejos dos impulsos perturbadores, não é a sua função original. Não lhes seria possível desempenhar essa função até que a totalidade da vida mental houvesse aceito a dominância do princípio de prazer. Se existe um "além do princípio de prazer", é coerente conceber que houve também uma época anterior em que o intuito dos sonhos foi a realização dos desejos (Freud, 1920a, p. 49).

Seguindo essas diretrizes, em um artigo póstumo, intitulado Reflexões sobre $o$ trauma, Ferenczi (2011e) realiza uma revisão de $A$ interpretação de sonhos (Freud, 1900/1990) e propõe uma função anterior à transformação dos restos diurnos em realização de desejo: "Penso, entretanto, que o retorno dos restos diurnos já representa por si mesmo uma das funçôes do sonho" (Ferenczi, 2011e, p. 128). De acordo com esse raciocínio, os restos diurnos são equiparados a restos de vida e considerados sintomas de repetição de traumas, tal como acontece com o mecanismo de compulsão à repetição na neurose traumática. A finalidade do retorno dos resíduos de vida no material onírico é de conduzir o trauma a uma resolução que não foi efetuada durante o atravessamento do acontecimento traumático originário. Assim, todo e qualquer sonho pode ser entendido como uma tentativa de elaboração de acontecimentos traumáticos.

Isso nos levar a crer que, sob a ótica ferencziana, a elaboração do trauma requer condiçôes especializadas que dependem de uma certa maturidade egoica. Como já foi visto, a ação psíquica do trauma conduz à aniquilação do sentimento de si, levando o sujeito à incapacidade de compreender e de nomear o que se passa; exigindo, assim, um grau de heroísmo do qual a criança ainda não é capaz. $\mathrm{O}$ que está em jogo, nessa situação, necessita de tradução, de uma ligação que ainda não foi realizada. Dessa forma, é possível entender que o sonho visa a dominar a angústia suscitada pelo choque traumático originário. Portanto, diante da angústia, a atividade onírica pode funcionar como uma tentativa de encontrar sentido para o que foi vivido e, assim, propiciar meios de converter o inominável em experiência psíquica traduzida e integrada ao ego. 
Por conseguinte, os restos do dia e da vida são impressões psíquicas tendentes à repetição não resolvidas e nem dominadas, inconscientes e que, talvez, jamais foram conscientes, as quais surgem mais nas condições do sono e do sonho do que em estado vígil, e exploram para seus fins a capacidade de realização de desejo no sonho (Ferenczi, 2011e, p. 129).

Para Ferenczi, a tendência à repetição do trauma é mais propícia durante o sono. Sem a ação da censura e do recalque, o conteúdo traumático encontra uma via que possibilita o acesso à consciência. Nesse sentido, os sonhos atualizam os acontecimentos traumáticos ocorridos na primeira infância. Em circunstâncias favoráveis, como na regressão, esses conteúdos emergem e reivindicam solução. Essa regressão pode ser entendida como o estado de sono, mas também pode ser vivida durante o processo analítico.

\section{CONSIDERAÇÕES FINAIS}

No caso de Pedro, entre os efeitos psíquicos (para além das sequelas cognitivas) das lesões cerebrais, em consequência dos AVE sofridos, observa-se, ao mesmo tempo, traços de uma neurose traumática e a atualização de traumas infantis. Ao se deparar com as limitações derivadas das sequelas dos AVE, Pedro se agarrou à ideia de que, "Se não dá para ser como antes, é melhor ficar quieto, não fazer mais nada", numa experiência (e desejo) de presente permanente, derivada da impossibilidade de atravessar a ruptura operada pelo adoecimento. Esse desígnio atualizava a exigência de ser forte e perfeito, despertando o sentimento de menos valia pelo insucesso em desempenhar certas tarefas.

Reagindo desse modo, Pedro permanecia imóvel, fixado, congelado: ainda que expressando seu esforço de superação, a compulsão à repetição atualizava incessantemente o desamparo infantil. Se retomarmos às considerações de Ferenczi a respeito dos sonhos traumáticos, é possível dizer que, no caso exposto, a experiência subjetiva das sequelas dos AVE desempenhava papel semelhante à função traumatolítica do sonho, posto que permitiam acesso direto a impressóes sensíveis não integradas ao funcionamento psíquico, em um movimento regressivo que convocava a analista a participar da cena traumática, tornando-o um vetor do que não pode ser expresso verbalmente pela rememoração.

Em 1928, Ferenczi propôs a noção de tato psicológico como norteadora da ação do analista. Tratava-se da capacidade de o analista perceber "quando e como se comunica alguma coisa ao analisando" (Ferenczi, 2011c, p. 27) e de estabelecer um contato empático com o paciente, cuja função seria possibilitar a compreensão emocional de "quando se deve calar e aguardar outras associações 
e em que momento o silêncio é uma tortura inútil para o paciente, etc." (p. 27). Definido como a faculdade de "sentir com", o tato supõe uma postura flexível "como uma tira elástica" que cede "às tendências do paciente, mas sem abandonar a tração" (Ferenczi, 2011c, p. 31-32) - que permita ao analista participar da sessão com seus próprios processos psíquicos em sintonia com seu paciente, ou seja, tornando-se parte do processo de simbolização com sua presença sensível. Noutras palavras, setting terapêutico e pessoa do analista seriam equivalentes, ou melhor, o setting seria parte integrante da personalidade do analista (Winnicott, 2000a, 2000b). De tal modo que, para essa linhagem de autores psicanalíticos, somente o oferecimento de um espaço analítico especializado, isto é, sensível e flexível seria capaz de possibilitar a construção narrativa da experiência traumática; inserindo-a em uma rede de sentidos e significaçôes. Nessa visada, a narratividade pode ser entendida como saída para o congelamento psíquico instaurado pela compulsão à repetição. No caso de Pedro, falar sobre si e situar a experiência de sofrimento no tempo impôs a tarefa de elaborar traumas precoces atualizados pelo aparecimento de lesões cerebrais, como uma espécie de fio que entrelaçava o tecido da existência e estabelecia uma continuidade entre os momentos iniciais do desenvolvimento infantil e que a experiência de adoecimento atualizava. 


\section{REFERÊNCIAS}

Balint, M. (1994). New beginning and the paranoid and the depressive syndromes. In M. Balint, Primary love and psycho-analytic techinique. (pp. 244265). London: Karnac.

Bion, W. R. (1994). A diferenciação entre a personalidade psicótica e a personalidade não psicótica. In W. R. Bion, Estudos psicanalíticos revisados. (pp. 45-62). Rio de Janeiro: Imago.

Bokanowisky, T. (2002). Traumatisme, traumatique, trauma. Revue Française de Psychanalyse, 66(3), 745-757.

Bokanowisky, T. (2005). Variations sur le concept de traumatisme: traumatisme, traumatique, trauma. Revue Française de Psychanalyse, 69(3), 891-905.

Ferenczi, S. (2011a). A criança mal acolhida e sua pulsão de morte. In S. Ferenczi. Obras completas: psicanálise IV. (pp. 53-68). São Paulo: Martins Fontes.

Ferenczi, S. (2011b). Confusão de línguas entre os adultos e as crianças. In S. Ferenczi. Obras completas: Psicanálise IV. (pp. 97-136). São Paulo: Martins Fontes.

Ferenczi, S. (2011c). Elasticidade da técnica psicanalítica. In S. Ferenczi. Obras completas: Psicanálise IV. (pp. 25-36). São Paulo: Martins Fontes.

Ferenczi, S. (2011d). O sonho do bebê sábio. In Obras completas: Psicanálise III. (pp. 223-224). São Paulo: Martins Fontes.

Ferenczi, S. (2011e). Reflexões sobre o trauma. In S. Ferenczi. Obras completas: Psicanálise IV. (pp. 109-117). São Paulo: Martins Fontes.

Freud, S. (1895/1950/1990). Projeto para uma Psicologia científica. In J. Salomão (Trad.), Edição standard brasileira das obras psicológicas completas de Sigmund Freud. (Vol. 1, pp. 403-587). Rio de Janeiro: Imago. (Publicado originalmente em 1895/1950).

Freud, S. (1897/1990). Carta 55. In J. Salomão (Trad.), Edição standard brasileira das obras psicológicas completas de Sigmund Freud. (Vol. 1, pp. 331-333). Rio de Janeiro: Imago. (Publicado originalmente em 1897).

Freud, S. (1900/1990). Interpretação de sonhos. In J. Salomão (Trad.), Edição standard brasileira das obras psicológicas completas de Sigmund Freud. (Vol. V, pp. 323-611). Rio de Janeiro: Imago. (Publicado originalmente em 1900). 
Freud, S. (1920a/1990). Além do princípio do prazer. In J. Salomão (Trad.), Edição standard brasileira das obras psicológicas completas de Sigmund Freud. (Vol. 18, pp. 17-89). Rio de Janeiro: Imago. (Publicado originalmente em 1920).

Freud, S. (1920b/1990). Suplemento à Teoria dos sonhos. In J. Salomão (Trad.), Edição standard brasileira das obras psicológicas completas de Sigmund Freud. (Vol. 18, pp. 95-111). Rio de Janeiro: Imago. (Publicado originalmente em 1920).

Freud, S. (1926/1990). Inibições, sintomas e ansiedade. In J. Salomão (Trad.), Edição standard brasileira das obras psicológicas completas de Sigmund Freud. (Vol. 20, pp. 70-168). Rio de Janeiro: Imago. (Publicado originalmente em 1926).

Freud, S. (1933/1990). Conferência XXXIV. In J. Salomão (Trad.), Edição standard brasileira das obras psicológicas completas de Sigmund Freud. (Vol. 22, pp. 135-154). Rio de Janeiro: Imago. (Publicado originalmente em 1933).

Freud, S. (1939/1990). Moisés e o monoteísmo: três ensaios. In J. Salomão (Trad.), Edição standard brasileira das obras psicológicas completas de Sigmund Freud. (Vol. 23, pp. 29-66). Rio de Janeiro: Imago. (Publicado originalmente em 1939).

Green, A. (1990). Conferências brasileiras de André Green: metapsicologia dos limites. Rio de Janeiro: Imago. (Publicado originalmente em 1986).

Heimann, P. (1995). Sobre a contratransferência. Revista de Psicanálise da Sociedade Psicanalitica de Porto Alegre, 2(1), 171-177. (Publicado originalmente em 1950).

Khan, M. (1984). O conceito de trauma cumulativo. In M. M. R. Khan, Psicanálise: teoria, técnica e casos clínicos. (pp. 57-75). Rio de Janeiro: Francisco Alves. (Publicado originalmente em 1963).

Lacan, J. (1986). O seminário, Livro I: os escritos técnicos de Freud. B. Milan, (Trad.). Rio de Janeiro: Jorge Zahar. (Publicado originalmente em 1953-1954).

Laplanche, J. \& Pontalis, J.-B. (1982). Vocabulário de psicanálise. São Paulo: Martins Fontes.

Ogden, T. (1994). The analytic third: Working with intersubjective clinical facts. International Journal of Psychoanalysis, 75(1), 3-19 
Roussillon, R. (2006). Paradoxos e situaçôes limites da psicanálise. São Leopoldo: Unisinos. (Publicado originalmente em 1991).

Winnicott, D. W. (2000a). Aspectos clínicos e metapsicológicos da regressão no contexto psicanalítico. In D. W. Winnicott, Da pediatria à psicanálise. (pp. 374-392). Rio de Janeiro: Imago. (Publicado originalmente em 1954).

Winnicott, D. W. (2000b). Retraimento e regressão. In D. W. Winnicott. Da pediatria à psicanálise. (pp. 347-354). Rio de Janeiro: Imago. (Publicado originalmente em 1954). 